\title{
Peran Moderasi Kinerja Pendamping Pada Pengaruh Program Keluarga Harapan Terhadap Pengentasan Kemiskinan di Kota Tanjungbalai
}

\author{
Dedeng Irawan \\ Muis Fauzi Rambe \\ Adi Munasib \\ Program Studi Magister Manajemen, Universitas Muhammadiyah Sumatera Utara Medan, Indonesia \\ Jl. Denai No. 217, Tegal Sari Mandala II, Medan Denai, Kota Medan, Sumatera Utara 20371 \\ Email : dedengirawan687@gmail.com
}

\begin{abstract}
Abstrak. Kesejahteraan sosial bagi seluruh masyarakat miskin dikota tanjungbalai merupakan tujuan dari utama yang ingin dicapai oleh walikota tanjungbalai. Salah satu upaya Pemerintah Kota Tanjungbalai untuk mencapai mengentaskan kemiskinan di Kota Tanjungbalai adalah dengan menghadirkan program pemerintah pusat yaitu Program Keluarga Harapan yang merupakan salah satu program andalan dari Kementrian Sosial Republik Indonesia yang dalam implementasinya masih sering mengalami masalah yang diakibatkan kurangnya pengetahuan akan program tersebut sehingga untuk mengatasi itu makan ditunjuklah pendamping sosial untuk membantu dalam mengaplikasikan program bantuan ini. Pendekatan penelitian yang digunakan adalah kuantitatif yang didukung dengan data primer dan sekunder. Jenis data yang digunakan adalah data primer yang didapat melalui penyebaran kuesioner kepada penerima PKH langsung. Teknik analisis data dimulai dari pengumpulan informasi melalui angket dalam bentuk pernyataan dan pada tahap akhir dengan menarik kesimpulan. Dari hasil penelitian menunjukkan bahwa secara signifikan variabel Program Keluarga Harapan mempengaruhi variabel Pengentasan Kemiskinan di Kota Tanjungbalai sehingga pemerintah Kota Tanjungbalai harus bisa mempertahankan program bantuan ini agar masyarakat Kota Tanjungbalai dapat terbantu. Sedangkan menurut hasil penelitian kinerja pendamping menunjukkan bahwa secara signifikan Variabel Kinerja Pendamping memoderasi hubungan Program Keluarga Harapan terhadap Pengentasan Kemiskinan di Kota Tanjungbalai yang artinya Kinerja Pendamping dapat memperkuan pelaksanaan kegiatan PKH Dikota Tanjungbalai.
\end{abstract}

Kata Kunci : Program Keluarga Harapan, Kinerja Pendamping, Pengentasan Kemiskinan

\begin{abstract}
Social welfare for all poor people in the city of Tanjungbalai is the main objective of the mayor of Tanjung Peninsula. One of the efforts of the City Government of Tanjungbalai to achieve poverty alleviation in the City of Tanjungbalai is by presenting a central government program, the Family of Hope Program which is one of the flagship programs of the Ministry of Social Affairs of the Republic of Indonesia, which in its implementation still often experiences problems due to lack of knowledge of the program so as to overcoming this problem, a social assistant was appointed to assist in applying this assistance program. The research approach used is quantitative supported by primary and secondary data. The type of data used is primary data obtained through distributing questionnaires to PKH recipients directly. The data analysis technique starts from gathering information through a questionnaire in the form of a statement and at the final stage by drawing conclusions. From the results of the study showed that significantly the Family Hope Program variable influences the variable Poverty Alleviation in the City of Tanjungbalai so that the government of the City of Tanjungbalai must be able to maintain this assistance program so that the people of the City of Tanjungbalai can be helped. Meanwhile, according to the results of the companion performance research, it was shown that the Comparative Performance Variable significantly moderated the relationship of the Hope Family Program on Poverty Alleviation in Tanjungbalai City, which meant that the Companion's Performance could strengthen the implementation of PKH activities in Tanjungbalai City
\end{abstract}

Keywords : Family Hope Program, Companion Performance, Poverty Alleviation 


\section{PENDAHULUAN}

Kemiskinan menjadikan Tanjungbalai mencari berbagai solusi yang pasti dalam mengurangi angka kemiskinan di Kota Tanjungbalai untuk menuju kehidupan yang lebih baik dalam memenuhi kebutuhannya. Kemiskinan merupakan permasalahan multi dimensional yang mencakup kemiskinan dalam dimensi ekonomi, kemiskinan dalam dimensi sosial, politik dan budaya, kemiskinan dalam dimensi kesehatan, pendidikan, sejarah, kemiskinan yang berdimensi pendidikan, agama, budi pekerti, serta dalam hubungan bilateral dan diplomasi. Dalam proses pembangunan yang terjadi di Indonesia dipengaruhi oleh dua dimensi yaitu yang pertama dimensi makro yang menggambarkan bagaimana institusi yang ada melalui kebijakan dan peraturan yang dibuat untuk mempengaruhi proses perubahan suatu masyarakat, sedangkan dimensi yang kedua adalah dimensi mikro yaitu individu dan kelompok masyarakat mempengaruhi proses pembangunan itu sendiri (BPS Tanjungbalai Tahun 2019).

Salah satu upaya Pemerintah Tanjungbalai dalam menanggulangi kemiskinan adalah melalui Program Keluarga Harapan $(\mathrm{PKH})$ yang merupakan program bantuan yang diberikan oleh Kementrian Sosial, akan tetapi untuk tingkat kabupaten/kota bekerja sama sama dinas sosial setempat. PKH mempunyai tujuan jangka pendek untuk membantu mengurangi beban pengeluaran Keluarga Penerima Manfaat (KPM) masyarakat kota Tanjungbalai, sedangkan untuk tujuan jangka panjang adalah untuk memutus rantai kemiskinan melalui bantuan PKH ini (DISPENDA Kota Tanjungbalai Tahun 2019).

Dinas Sosial adalah sebuah lembaga pemerintahan yang menanggulangi dan mengatasi permasalahan sosial yang timbul dimasyarakat dalam rangka mencapai kesejahteraan sosial bagi masyarakat. Dinas Sosial Kota Tanjungbalai terletak di Jalan Jendral Sudirman KM 1,5, Kelurahan Sirantau, Kecamatan Datuk Bandar, Kota Tanjung Balai, Sumatera Utara 21332. Dinas Sosial Kota Tanjungbalai merupakan Satuan Kerja Pemerintahan Daerah Kota Tanjungbalai yang mempunyai tugas melaksanakan urusan pemerintahan daerah di bidang sosial berdasarkan asas otonomi yang menjadi kewenangan, tugas dekonsentrasi dan tugas pembantuan yang diberikan pemerintah kepada Walikota serta tugas lain sesuai dengan kebijakan yang ditetapkan oleh Walikota berdasarkan peraturan perundangundangan yang berlaku.

Visi Dinas Sosial Kota Tanjungbalai adalah dapat mewujudkan Kesejahteraan Sosial Masyarakat Kota Tanjungbalai. Untuk dapat mewujudkan visi tersebut, Dinas Sosial Kota Tanjungbalai mempunyai Misi sebagai berikut : meningkatkan kualitas sumber daya manusia pelaku penyelenggaraan kesejahteraan sosial, meningkatkan penyelenggaran pemberdayaan sosial sebagai metode penanggulangan kemiskinan, meningkatkan penyelenggaraan perlindungan sosial, jaminan sosial dan rehabilitasi sosial dalam bentuk bantuan sosial, dan atau asistensi sosial untuk menjamin pemenuhan dasar dan pemulihan fungsi sosial PMKS (Penyandang Masalah Kesejahteraan Sosial), memelihara dan melestarikan nilai-nilai kepahlawanan dan semangat kejuangan.

Bagi para penerima PKH diharapkan dapat membantu peningkatan kehidupannya kepada taraf hidup yang lebih baik dalam hal pendidikan dan kesehatan, sedangkan bagi pemerintah kota Tanjungbalai program ini diharapkan berkesinambungan dan mampu memberikan kontribusi untuk mempercepat pencapaian tujuan pembangunan millenium (millenium development goals atau MDGs). Setidaknya ada 5 komponen MDGs yang didukung melalui $\mathrm{PKH}$, yaitu pengurangan penduduk miskin ekstrim dan kelaparan, pencapaian pendidikan dasar, kesetaraan gender, pengurangan angka kematian bayi dan balita, dan pengurangan kematian ibu melahirkan. Sehingga pemerintah kota Tanjungbalai sangat welcome dengan hadirnya program ini dikota Tanjungbalai yang dirancang untuk membantu penduduk miskin kluster terbawah berupa bantuan tunai bersyarat. 
PKH di Kota Tanjungbalai mulai dilaksanakan pertama kali pada akhir tahun 2015 akan tetapi secara nasional PKH hadir pada tahun 2007, dengan memberikan bantuan dana untuk dua komponen yaitu bidang kesehatan dan juga bidang pendidikan. Sasaran dari program ini yakni ibu hamil, ibu menyusui, anak balita, anak pra sekolah (apras), sedangkan untuk anak usia sekolah setingkat Sekolah Dasar (SD) dan sederajat, Sekolah Mengengah Pertama (SMP) dan sederajat, dan Sekolah Menengah Atas (SMA) dan Sederajat. sehingga anak pada usia 6 (enam) sampai 21 (dua puluh satu) tahun harus menyelesaikan wajib belajar 12 tahun. Selanjutnya pada pelaksanaan PKH tahun 2016 terdapat penambahan komponen kesejahteraan sosial dengan masuknya Penyandang Disabilitas Berat (PDB) dan lanjut usia (lansia) guna membantu masyarakat miskin yang memiliki fisik yang tidak sempurna dan harus dibantu dalam melakukan aktifitas nya sehari-hari dan bagi masyarakat yang sudah lanjut usia diatas 70 tahun mendapatkan bantuan PKH.

Selain itu tujuan diberlakukannya PKH dalam jangka panjang adalah untuk memutus mata rantai kemiskinan, meningkatkan kualitas sumber daya manusia, serta merubah prilaku RTM yang relatif kurang mendukung peningkatan kesejahtraan dari kelompok miskin. Tujuan tersebut sekaligus mendukung dalam upaya mempercepat pencapaian target Millennium Development Goals (MGDs). Ada lima komponen MGDs yang secara tidak langsung akan terbantu oleh PKH, yaitu mencakup: Pengurangan penduduk miskin dan kelaparan, Pendidikan dasar, Kesetaraan jender, Pengurangan angka kematian bayi dan balita, dan Pengurangan kematian ibu melahirkan. Secara khusus, tujuan PKH adalah meningkatkan akses dan pelayanan pendidikan dan kesehatan,meningkatkan taraf pendidikan peserta PKH, meningkatan status kesehatan dan gizi ibu hamil/nifas dan balita dibawah lima tahun, anak pra sekolah RTM atau peserta PKH.

Dalam pelaksanaan PKH, terdapat pendamping yang merupakan aktor penting dalam mensukseskan program PKH. Pendamping PKH adalah sumber daya manusia yang direkrut dan dikontrakkerjakan yang ditetapkan oleh Kementerian Sosial sebagai pelaksana pendampingan di tingkat kecamatan. Keberhasilan PKH dipengaruhi oleh implementasi pemberdayaan masyarakat miskin (RTSM) dan peran pendamping. Menurut Departemen Sosial (Tahun 2009), pendampingan sosial merupakan suatu proses relasi sosial antara pendamping dengan klien yang bertujuan memecahkan masalah, memperkuat dukungan, mendayagunakan berbagai sumber dan potensi dalam pemenuhan kebutuhan hidup, serta meningkatkan akses klien terhadap pelayanan sosial dasar, lapangan kerja, dan fasilitas pelayanan publik lainnya.

Berdasarkan pengertian yang dimaksud peran pendamping adalah suatu tugas atau aktivitas yang dilakukan oleh seseorang yang menjadi penghubung masyarakat dengan berbagai lembaga terkait dan diperlukan bagi pengembangan. Pendamping sering dikaitkan dengan pekerja sosial dan kegiatan pendampingan merupakan pekerjaan sosial. Ada beberapa Undang-Undang yang secara langsung mengakui dan mengatur adanya keberadaan pekerja sosial. Diantaranya Undang-Undang Nomor 11 tahun 2009 tentang Kesejahteraan Sosial.

Berdasarkan permasalahan dan beberapa teori serta adanya penelitian terdahulu yang telah di jelaskan di atas, dapat diketahui bahwa bagaimana sesungguhnya pengaruh Program Keluarga Harapan terhadap pengentasan kemiskinan di kota Tanjungbalai dimoderasi kinerja pendamping yang telah berdiri dari tahun 2015 sampai sekarang yang meliputi pelaksanaan kegiatan PKH, permasalahan / penghambat, dan faktor pendukung terhadap masyarakat yang menjadi Keluarga Penerima Manfaat di Kota Tanjungbalai.. 


\section{LANDASAN TEORI}

\section{Ekonomi Masyarakat Peserta PKH}

Dimensi kemiskinan yang begitu luas mengharuskan setiap upaya penanggulangan kemiskinan perlu dilakukan secara terpadu yang meliputi berbagai program pembangunan baik secara sektoral maupun regional. Undang-Undang Dasar Tahun 1945 telah mengamanatkan negara untuk melindungi segenap bangsa Indonesia dan memajukan kesejahteraan umum dalam rangka mewujudkan keadilan sosial bagi seluruh rakyat Indonesia. Dalam dokumen Rencana Pembangunan Jangka Menengah Nasional (RPJM) yang ditetapkan melalui Perpres Nomor 5 Tahun 2010 tertulis, kebijakan penanggulangan kemiskinan berada di urutan ke-4 dari 11 daftar prioritas nasional. Dalam dokumen tersebut ditetapkan target untuk menurunkan tingkat kemiskinan ke angka 8-10 persen di akhir 2014. Pemberdayaan ekonomi rakyat dan kemiskinan adalah masalah pokok dan isu sentral pembangunan ekonomi dan sosial yang pada saat ini hingga beberapa tahun mendatang masih tetap relevan untuk terus dikaji di Indonesia. Pemberdayaan ekonomi masyarakat adalah proses perolehan pelaku ekonomi untuk mendapatkan surplus value sebagai hak manusia yang terlibat dalam kegiatan produksi. Upaya ini dapat dilakukan melalui distribusi penguasaan faktor-faktor produksi (melalui kebijakan politik ekonomi yang tepat dengan kondisi dan tingkatan sosial ekonomi budaya masyarakat setempat). Permasalahan yang dialami oleh masyarakat miskin menunjukkan bahwa kemiskinan bersumber dari ketidakberdayaan dan ketidakmampuan masyarakat dalam memenuhi hak-hak dasar mereka sebagai masyarakat miskin. Oleh karena hal tersebut, pemerintah selalu berupaya untuk melakukan koordinasi antar pihak dalam upaya penanggulangan kemiskinan di berbagai aspek melalui program-program strategis dan sistematis (Haryati, 2007).

\section{Kemiskinan}

Dari banyaknya definisi kemiskinan kemudian dikaji kembali dan diperluas berdasarkan permasalahan-permasalahan dan faktor-faktor yang penyebab kemiskinan. Kajian tersebut dapat terlihat pada definisi kemiskinan yang dikemukakan oleh bebrapa pendapat berikut : Menurut Buku Putih, Penanggulangan Kemiskinan di Indonesia (2002:2) menyatakan bahwa Kemiskinan telah menjadi masalah yang kronis karena berkaitan dengan kesenjangan dan pengangguran. Jadi pemecahannya pun harus terkait dan komprehensif dengan faktor-faktor yang mempengaruhinya. Sedangkan Menurut Undang-undang No. 24 tahun 2004 menyatakan bahwa Kemiskinan adalah kondisi sosial ekonomi seseorang atau sekelompok orang yang tidak terpenuhi atas hak-hak dasarnya untuk mempertahankan dan mengembangkan kehidupan yang bermartabat. Serta Menurut Sadewo, FX Sri, dkk, (2007:28) menyatakan bahwa : Kemiskinan dapat pula dipandang sebagai salah satu akibat dari kegagalan dari kelembagaan pasar (bebas) dalam mengalokasikan sumberdaya yang terbatas secara adil kepada seluruh anggota masyarakat. Dari beberapa pendapat diatas dapat disimpulkan bahwa kemiskinan adalah suatu kondisi ketidakmampuan dalam melakukan kegiatan usaha produktif, menjangkau akses sumber daya sosial ekonomi, menentukan nasibnya sendiri dan senantiasa mendapatkan perlakuan diskriminatif, dan membebaskan diri dari mental dan budaya miskin seseorang atau keluarga yang untuk memenuhi kebutuhan dasar saja belum mampu untuk memenuhinya.

\section{Program Keluarga Harapan (PKH)}

PKH lebih dimaksudkan sebagai upaya membangun sistem perlindungan sosial kepada masyarakat miskin dalam rangka meningkatkan kesejahteraan sosial penduduk miskin sekaligus sebagai upaya memutus rantai kemiskinan yang terjadi selama ini dengan cara 
memberikan bantuan yang lebih ditujukan untuk digunakan untuk membiayai kesehatan dan pendidikan anak-anak mereka. PKH merupakan program bantuan dan perlindungan sosial yang termasuk dalam klaster I strategi penanggulangan kemiskinan di Indonesia yang berkaitan dengan pendidikan, kesehatan dan pemenuhan dasar bagi lansia dan penyandang disabilitas berat (Pedum PKH Tahun 2019). Menurut Buku saku Pendamping dan Operator PKH (Tahun 2015:2). Program Keluarga Harapan (PKH) adalah program pemberian bantuan tunai bersyarat kepada keluarga sangat miskin (KSM) yang memenuhi syarat kepesertaan dan ditetapkan oleh kementrian sosial.

\section{Kinerja Pendamping PKH}

Program Keluarga Harapan (PKH) didukung oleh pendamping dengan pendidikan relatif tinggi dan berlatar belakang disiplin ilmu yan mendukung untuk perubahan sikap dan prilaku, selain itu pengembangan karier sebagai seorang pendamping $\mathrm{PKH}$ hanya berupa prestasi kerja, maka dari itu kinerja pendamping PKH lebih unggul dibanding kelemahannya dengan sistem kontrak, keterampilan penunjang dan konsekuensi jarak tempuh ketempat kerja. Beberapa pendapat tentang kinerjan menyatakan bahwa : Menurut Fadri Hayatul (2017:418) Kinerja merupakan kombinasi dari faktor-faktor motivasi (motivation), dengan upaya (effort), kemampuan (ability) dan ketepatan persepsi (accuracy of perception). Sedangkan menurut Rivai (2006:309-310), menyatakan bahwa :Kinerja adalah hasil kerja konkret yang dapat diamati dan dapat diukur. Penilaian kinerja mengacu pada Suatu sistem formal dan terstruktur yang digunakan untuk mengukur, menilai dan mempengaruhi sifat-sifat yang berkaitan dengan pekerjaan, perilaku dan hasil, termasuk tingkat ketidakhadiran. Dari beberapa pendapat diatas dapat ditarik kesimpulan bahwa kinerja merupakan upaya yang dilakukan untuk memacu kemampuan dalam kerja agar mencapai hasil yang konkret dala dunia pekerjaan.

\section{Pengaruh Program Keluarga Harapan Terhadap Pengentasan Kemiskinan.}

Program Keluarga Harapan (PKH) merupakan program perlindungan sosial yang memberikan bantuan berupa uang tunai kepada Rumah Tangga Miskin (RTM) berdasarkan persyaratan dan ketentuan yang telah ditetapkan dengan melaksanakan kewajibannya. Tujuan PKH dalam jangka panjang adalah untuk memutus mata rantai kemiskinan, meningkatkan kualitas sumber daya manusia melalui peningkatan kualitas pendidikan dan kesehatan. Berdasarkan Peraturan Menteri Sosial Republik Indonesia No. 1 Tahun 2018 menyatakan bahwa : Program Keluarga Harapan ditetapkan untuk mendukung pelaksanaan penyaluran program perlindungan sosial yang terencana, terarah, dan berkelanjutan dalam bentuk Program Keluarga Harapan (PKH) sebagai bantuan sosial bersyarat yang bertujuan untuk mengurangi beban pengeluaran dan meningkatkan pendapatan keluarga miskin dan rentan. Penyaluran bantuan sosial PKH sebagai salah satu upaya mengurangi kemiskinan dan kesenjangan dengan mendukung perbaikan aksesibilitas terhadap layanan kesehatan, pendidikan, dan kesejahteraan sosial guna meningkatkan kualitas hidup keluarga miskin dan rentan.

Program Keluarga Harapan (PKH) dalam mengentaskan kemiskinan menurut Kartiawati (2017:107) menyatakan bahwa : PKH di Kampung Bonglai yang dimulai sejak tahun 2014-2017 yang bertujuan untuk mengentasakan kemiskinan, salah satunya adalah di Kampung Bonglai kurang terlaksana secara efektif. Sedangkan menurut Saraswati Aprilia (2018:118) menyatakan bahwa : Program Keluarga Harapan (PKH) berpengaruh negatif dan signifikan terhadap pengentasan kemiskinan di Pekon Pandansurat. Akan tetapi hal ini bertolak belakang dengan hasil penelitian Firma Kusuma Indrayani (2014:6), dalam jurnalnya yang berjudul Efektivitas Program Keluarga Harapan di Desa Sugihwaras Kecamatan Saradan Kabupaten Madiunmengemukakan bahwa: PKH di desa Sugihwaras Kecamatan Saradan 
Kabupaten Madiun adalah suatu program yang sangat efektif untuk membantu RTSM dalam bidang pendidikan dan kesehatan. Hal ini disebabkan dengan hasil presentase subvariabel peningkatan akses pendidikan dan kesehatan yang mencapai 88\%. Dari beberapa hasil penelitian maupun pendapat yang telah meneliti tentang $\mathrm{PKH}$ diatas, peneliti menarik kesimpulan bahwa Program Keluarga Harapan berpengaruh terhadap pengentasan kemiskinan.

\section{Peran Moderasi Kinerja Pendamping terhadap kegiatan PKH.}

Untuk melakukan pendampingan terhadap peserta $\mathrm{PKH}$, pendamping harus membagi mereka dalam beberapa kelompok yang memudahkan dalam proses pendampingan sehingga kinerja pendamping akan lebih efektif dalam mendampingi para peserta $\mathrm{PKH}$ dan memastikan bahwa program $\mathrm{PKH}$ sebagai program penanggulangan kemiskinan dalam menyalurkan bantuan PKH kepada peserta PKH. Peran pendamping Program keluarga Harapan menurut Kementrian Sosial RI tahun 2015 menyatakan bahwa Melakukan pendampingan dan advokasi kepada peserta PKH agar bisa memperoleh haknya sebagai peserta PKH maupun untuk mendapatkan hak-hak program komplementaritas, yang meliputi Program Indonesia Pintar (PIP), Program Indonesia Sehat (PIS), Program Simpanan Keluarga Sejahtera(PSKS), dan bantuan beras miskin (RASKIN) serta program penanggulangan kemiskinan, meliputi Kelompok Usaha Bersama (KUBE), Usaha Ekonomi Produktif (UEP), Rumah Tinggal Layak Huni.

Berdasarkan hasil penelitian (Utari 2018:98) Mengenai Kinerja Pelaksana PKH Kecamatan Ujungberung dapat disimpulkan, bahwa : Dalam dimensi kualitas (quality), Pelaksana PKH Kecamatan sudah memiliki skill komunikasi yang baik yang dibuktikan dari tingkat antusiasme peserta PKH dalam mendengarkan arahan dari pelaksana PKH Kecamatan. Tidak hanya itu, keluasan pengetahuan dari Pelaksana PKH Kecamatan dapat dilihat dari jawaban yang disampaikan dalam forum diskusi. Sedangkan menurut Suradi dan Mujiyadi B (2018:142) menyatakan bahwa Kinerja Pendamping Sosial pada Program Penanganan Kemiskinan dan Kelompok Rentan di Kota Tarakan pada kategori sedang (moderate). Hal ini didasarkan penilaian pada: pelaksanaan kegiatan (preventif, kuratif/rehabilitatif dan pengembangan) dan peranan (penjalin sumber, motivator, pendidik dan fasilitator); pengembangan jejaringan /kemitraan dengan sistem sumber; dan permasalahan-permasalahan yang masih dihadapi dalam melaksanakan pendampingan sosial.

\section{METODE PENELITIAN}

Pendekatan penelitian merupakan cara atau metode yang digunakan oleh peneliti guna memperoleh data terkait masalah yang diteliti, dan pada penelitian kali ini peneliti akan menggunakan metodelogi penelitian kuantitatif. Metode pengumpulan data yang digunakan dalam penelitian ini yaitu angket atau kuesioner. Peneliti akan mengumpulkan data dengan cara Kuesioner yaitu dengan menyebarkan angket kepada para responden yang dalam hal ini pendamping $\mathrm{PKH}$ dan keluarga penerima manfaat program keluarga harapan di kota Tanjungbalai, dibuat dalam bentuk pertanyaan yang bersifat tertutup, setiap objek diminta untuk memilih salah satu alternatif jawaban yang telah ditentukan. Penelitian ini menganalisis peran moderasi kinerja pendamping pada pengaruh program keluarga harapan terhadap pengentasan kemiskinan dikota Tanjungbalai. Metode yang digunakan dalam penelitian ini adalah metode Moderated Regression Analysis (MRA) dengan menggunakan program software Statistical Package for Social Sciences (SPSS). 


\section{HASIL DAN PEMBAHASAN}

\section{Hasil Penelitian}

Uji normalitas digunakan untuk menguji apakah model regresi mempunyai distribusi normal ataukah tidak. Asumsi normalitas merupakan persyaratan yang sangat penting pada pengujian kebermaknaan (signifikansi) koefisien regresi. Model regresi yang baik adalah model regresi yang memiliki distribusi normal atau mendekati normal, sehingga layak dilakukan pengujian secara statistik.

Pengujian secara visual dapat juga dilakukan dengan metode gambar normal Probability Plots dalam software IBM SPSS.

\section{Gambar 1. Output SPSS Charts Normal P Plot}

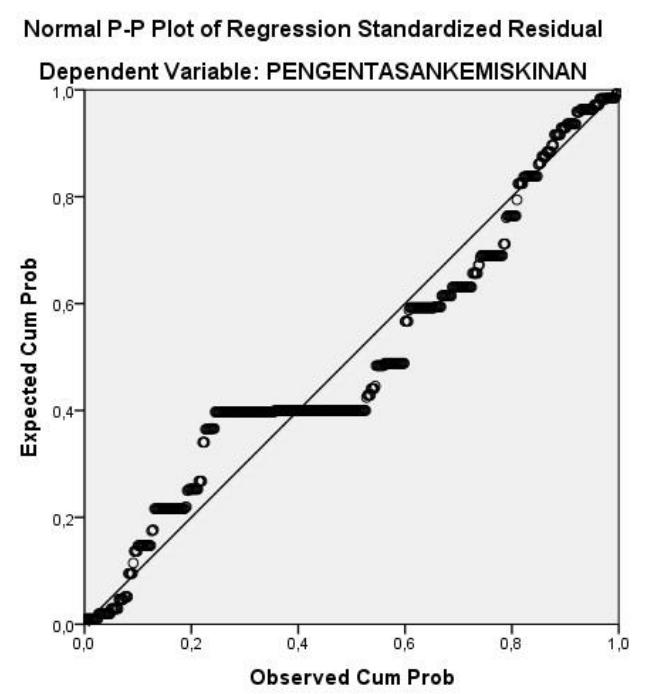

Gambar 4.2

\section{Output SPSS Charts Normal P Plot}

Menurut tampilan chart di atas dapat melihat grafik histrogram maupun grafik plot. Dimana grafik histrogram memberikan pola distribusi melenceng kekanan yang artinya adalah data berdistribusi normal. Selanjutnya, pada gambar P.Plot terlihat titik-titik mengikutti dan mendekati garis diagonalnya sehingga dapat disimpulkan bahwa model regresi memenuhi asumsi normalitas.

Uji Heteroskedastisitas digunakan untuk mengetahui ada atau tidaknya kesamaan varian dari residual (nilai eror) dari nilai observasi yang satu dengan observasi yang lain. Uji heteroskedastisitas juga dapat dilakukan dengan mengamati grafik scatterplot hasil analisis program SPSS. Berikut uraian uji heteroskedastisitas penelitian :

Tabel 1. Tabel Output SPSS Uji heteroskedastisitas

\begin{tabular}{|c|c|c|c|c|c|c|}
\hline \multicolumn{7}{|c|}{ Coefficients $^{a}$} \\
\hline \multirow{2}{*}{\multicolumn{2}{|c|}{ Model }} & \multicolumn{2}{|c|}{ Unstandardized Coefficients } & \multirow{2}{*}{$\begin{array}{c}\begin{array}{c}\text { Standardized } \\
\text { Coefficients }\end{array} \\
\text { Beta } \\
\end{array}$} & \multirow[b]{2}{*}{$t$} & \multirow[b]{2}{*}{ Sig. } \\
\hline & & $\mathrm{B}$ & Std. Error & & & \\
\hline \multirow[t]{3}{*}{1} & (Constant) & 15,149 & 3,308 & & 4,580 & 249 \\
\hline & $\mathrm{PKH}$ &, 733 &, 036 &, 658 & 20,514 &, 449 \\
\hline & KINERJAPENDAMPING &, 130 &, 026 &, 162 & 5,054 & 962 \\
\hline
\end{tabular}

Dari output diatas, maka tampak bahwa kedua variabel diatas tidak ada gejala heteroskedastisitas karena Sig > 0,05 


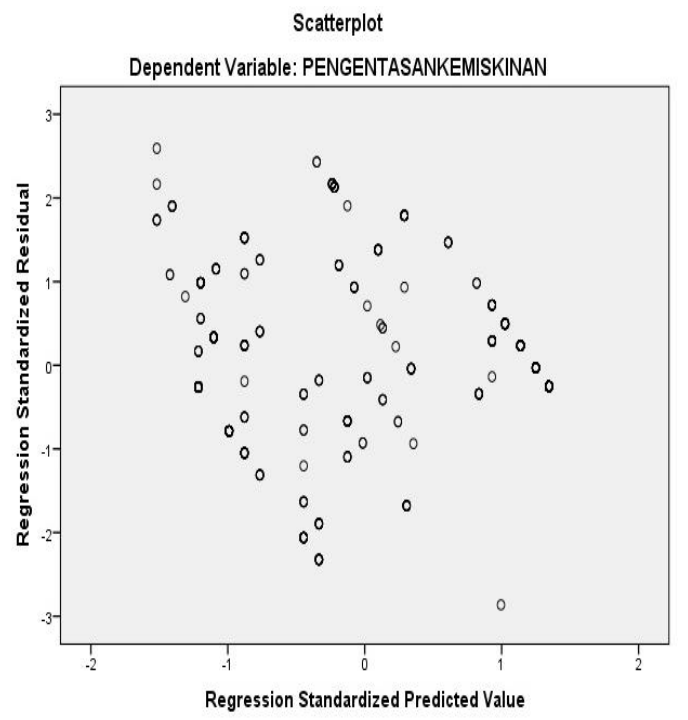

\section{Gambar 2. Output SPSS Charts Scaterplot}

Berdasarkan output Scatterplots di atas diketahui bahwa :

1) Titik-titik data penyebar di atas dan di bawah atau sekitar angka 0

2) Titik-titik tidak mengumpul hanya di atas atau di bawah saja.

3) Penyebaran titik-titik data tidak membentuk pola bergelombang melebar kemudian menyempit dan melebar kembali.

4) Penyebaran titik-titik data tidak berpola

Dengan demikian dapat disimpulkan bahwa tidak terjadi masalah heteroskedastisitas, hingga model regresi yang baik dan ideal dapat terpenuhi.

\section{Analisis Moderasi}

Dalam penelitian ini, untuk melihat pengaruh Program Keluarga Harapan Terhadap Pengentasan Kemiskinan di kota Tanjungbalai, peneliti akan menggunakan menganalisis menggunakan analisis regresi linear berganda, yaitu sebagai berikut :

Tabel 2. Tabel Output SPSS Uji Regresi Linear Berganda

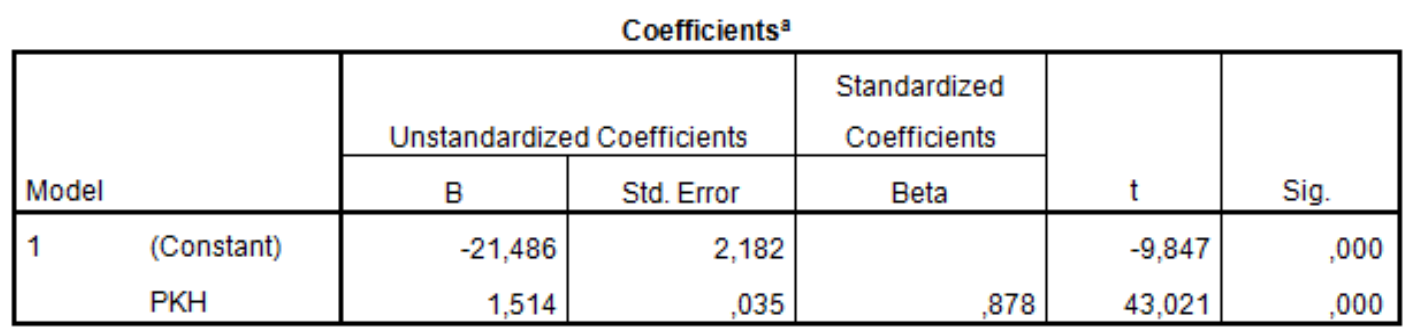

a. Dependent Variable:PENGENTASANKEMISKINAN

Berdasarkan data diatas, didapatkan nilai Sig untuk PKH adalah sebesar 0,000 $(\mathrm{p}<0,05)$ maka dari itu hipotesis diterima, artinya variabel PKH berpengaruh signifikan terhadap pengentasan kemiskinan di kota Tanjungbalai.

Selain itu, penelitian ini juga akan menganalisis peran moderasi kinerja pendamping pada pengaruh program keluarga harapan terhadap pengentasan kemiskinan dikota Tanjungbalai. Dalam analisis ini, akan dapat dilihat apakah variabel kinerja pendamping dapat memperkuat atau memperlemah kegiatan PKH dalam mengentaskan kemiskinan di kota 
Tanjungbalai, metode yang digunakan dalam penelitian ini adalah metode Moderated Regression Analysis (MRA) dengan menggunakan program software Statistical Package for Social Sciences (SPSS). Dan hasil nya adalah sebagai berikut :

\section{Tabel 3. Tabel Output SPSS MRA}

\section{Model Summary}

\begin{tabular}{l|c|c|c|r|}
\hline Model & $\mathrm{R}$ & R Square & $\begin{array}{c}\text { Adjusted R } \\
\text { Square }\end{array}$ & $\begin{array}{c}\text { Std. Error of } \\
\text { the Estimate }\end{array}$ \\
\hline 1 &, $664^{\text {a }}$ &, 441 &, 438 & 5,913 \\
\hline
\end{tabular}
a. Predictors: (Constant), PKH KINERJAPENDAMPING,
KINERJAPENDAMPING, PKH

Nilai output $\mathrm{R}$ Square pertama sebesar 0,412 atau atau $42,1 \%$ sedangkan setelah dilakukan pengujian nilai output $\mathrm{R}$ Square yang kedua naik menjadi 0,441 atau 44,1\%. Dengan melihat hasil diatas, dapat disimpulkan bahwa dengan adanya kinerja pendamping (variabel moderator) akan dapat memperkuat hubungan $\mathrm{PKH}$ terhadap pengentasan kemiskinan.

\section{Pembahasan}

Berdasarkan hasil penelitian yang dilakukan, diperoleh hasil dari analisis yang mempengaruhi pengentasan kemiskinan di kota Tanjungbalai yang dipaparkan berikut ini :

\section{Pengaruh Program Keluarga Harapan terhadap pengentasan kemiskinan.}

Berdasarkan pengujian hipotesis diatas, dapat disimpulkan bahwa Program Keluarga Harapan berpengaruh signifikan terhadap pengentasan kemiskinan di kota Tanjungbalai dengan nilai koefisien regresi sebesar 1,514. Artinya setiap kenaikan PKH 1 Satuan mengakibatkan pengentasan kemiskinan dapat dilakukan sebesar 1,514. Hasil ini sejalan dengan hasil penelitian Munawwarah Sahib (2016:99) yang menyatakan bahwa terbukti bahwa Program Keluarga Harapan memiliki pengaruh yang signifikan terhadap penanggulangan kemiskinan. Hal tersebut memberikan arti bahwa dengan adanya Program Keluarga Harapan yang dilaksanakan dengan sangat baik oleh pemerintah dan seluruh unsur yang terkait dapat membantu menanggulangi kemiskinan di Kecamatan Bajeng Kabupaten Gowa. Program Keluarga Harapan merupakan program bantuan dan perlindungan sosial yang termasuk dalam klaster pertama strategi penanggulangan kemiskinan di Indonesia. Program ini merupakan bantuan tunai bersyarat yang berkaitan dengan persyaratan pendiidikan dan kesehatan. Kesinambungan dari program ini akan berkontribusi dalam mempercepat Tujuan Pembangunan Milenium (Millennium Development Goals). Karena setidaknya ada 5 komponen tujuan MDGs yang didukung melalui PKH, yaitu penanggulangan kemiskinan ekstrim dan kelaparan, pencapaian pendidikan dasar untuk semua, pemberdayaan perempuan, pengurangan angka kematian anak dan peningkatan kesehatan ibu.

Dari segi pelaksanaan Program Keluarga Harapan, sebagaimana hasil penelitian menunjukkan bahwa PKH berjalan dengan baik. Sehingga dengan pengimplementasian program tersebut dengan baik dan sesuai dengan ketentuan yang telah ditetapkan, maka diharapkan hal tersebut dapat menjadi jalan bagi bangsa Indonesia untuk mencapai tujuannya dalam menanggulangi kemiskinan dan mewujudkan kesejahteraan bagi seluruh rakyat Indonesia. Meskipun hal tersebut memerlukan waktu yang panjang, namun dengan pencapaian tujuan jangka panjang PKH yaitu memutus mata rantai kemiskinan antar generasi maka generasi-generasi dari keluarga miskin kelak dapat keluar dari kemiskinan. Ini dapat terwujud jika anak-anak dari keluarga miskin mendapat pendidikan dan pelayanan kesehatan yang layak. Oleh karena itu, PKH mengutamakan pemenuhan pendidikan dan pelayanan kesehatan pada 
anak-anak dari keluarga miskin agar kelak mereka tidak jatuh pada kondisi yang sama dengan orangtua mereka. Maka dari itu dapat disimpulkan bahwa dalam pelaksanaan PKH di kota Tanjungbalai berjalan dengan baik sehingga kedepannya program bantuan ini dapat terus berjalan dan seluruh masyarakat miskin bisa memperoleh bantuan PKH agar tujuan jangka panjang PKH yaitu memutus rantai kemiskinan dapat tercapai.

\section{Kinerja Pendamping dapat Memperkuat atau Memperlemah kegiatan PKH.}

Berdasarkan hasil pengujian hipotesis diatas menunjukkan bahwa Nilai output $\mathrm{R}$ Square pertama sebesar 0,412 atau atau $42,1 \%$ sedangkan setelah dilakukan pengujian nilai output R Square yang kedua naik menjadi 0,441 atau 44,1\%. Dengan melihat hasil diatas, dapat disimpulkan bahwa dengan adanya kinerja pendamping (variabel moderator) akan dapat memperkuat hubungan PKH terhadap pengentasan kemiskinan. secara parsial dengan metode Moderated Regression Analysis (MRA) diperoleh kesimpulan bahwa kinerja pendamping menjadi memperkuat pelaksanaan PKH sehingga terjadi hubungan moderasi dengan pengaruh PKH terhadap pengentasan kemiskinan di kota Tanjungbalai. Dari kesimpulan ini diperoleh dari hasil nilai koefisien $\beta$ variabel moderat yang memiliki tanda positif dan signifikan terhadap $\alpha$. Variabel moderat merupakan variabel baru hasil interaksi variabel nilai PKH dan kinerja pendamping. Hal ini mengindikasikan bahwa kinerja pendamping memiliki pengaruh terhadap hubungan antara PKH dan pengentasan kemiskinan di kota Tanjungbalai.

Pendamping PKH memiliki tugas yang sangat penting sebagai pelaksana PKH yang paling dekat dengan masyarakat yang menjadi peserta PKH. Setiap bulan para pendamping harus melakukan pertemuan rutin dengan para KSM peserta PKH. Pertemuan ini dilakukan untuk berbincang-bincang dengan peserta mengenai perkembangan masyarakat setelah menerima bantuan, untuk mengontrol mereka agar bantuan benar-benar dipergunakan sebagaimana mestinya. Selain itu dalam setiap pertemuan pendamping akan senantiasa mendengar keluhan dari peserta PKH seputar bantuan PKH ataupun masalah pendidikan dan kesehatan jika mereka memiliki kendala yangkemudian keluhan itu akan dikemukakan dalam rapat di UPPKH Kabupaten/Kota untuk dapat ditindaklanjuti dan diberikan solusi. Hal-hal tersebut ternyata juga dilaksanakn dengan baik oleh para pendamping PKH di Kota Tanjungbalai.

Hasil penelitian menunjukkan bahwa kinerja pendamping menjadi faktor penguat Program Keluarga Harapan terhadap pengentasan kemiskinan di kota Tanjungbalai sehingga berpengaruh positif dan signifikan. Meskipun kelihatannya pengaruh tersebut tidak begitu besar, namun untuk suatu usaha penanggulangan kemiskinan hasil tersebut bukan hasil yang rendah tetapi telah cukup tinggi dan dapat dilihat pada kenyataannya yang sangat dirasakan manfaatnya oleh para peserta PKH Dan jika pelaksaan Program Keluarga Harapan terus menerus dilakukan dengan baik dan ditingkatkan maka hasilnya atau pengaruhnya terhadap penanggulangan kemiskinan juga akan lebih besar.

\section{KESIMPULAN}

Berdasarkan hasil penelitian dan pembahasan diatas, maka dari penelitian ini dapat di kesimpulkan bahwa beberapa hal antara lain : Hasil penelitian menunjukkan bahwa secara signifikan variabel Program Keluarga Harapan (PKH) mempengaruhi variabel Pengentasan Kemiskinan di Kota Tanjungbalai dan Hasil penelitian menunjukkan bahwa secara Variabel Kinerja Pendamping memoderasi hubungan Program Keluarga Harapan (PKH) terhadap Pengentasan Kemiskinan di Kota Tanjungbalai. Berdasarkan kesimpulan dari hasil penelitian ini, maka Peneliti memberikan beberapa saran sebagai berikut: Disarankan kepada pihak Pemerintah Kota Tanjungbalai agar terus melanjutkan Program Keluarga Harapan agar 
masyarakat miskin di Kota Tanjungbalai dapat terbantu. Bagi Pendamping PKH disarankan agar terus meningkatkan dan mengoptimalkan kinerja nya agar program bantuan ini dapat berjalan dengan lancar dan terus bergulir sampai masyarakat miskin baik di kota Tanjungbalai maupun daerah lain bisa keluar dari kemiskinannnya sesuai degnan tujuan PKH yaitu meemutus rantai kemiskinan.

\section{DAFTAR PUSTAKA}

Arikunto, (2015), Menajemen Penelitian (Edis Kelima). Jakarta. Penerbit PT.Rineka Cipta.

Antoro, Hajar Hari. 2015. Efektivitas Pelaksanaan Program Keluarga Harapan di Bidang Pendidikan Di Desa Sungai Kakap Kabupaten Kubu Raya, Skripsi tidak diterbitkan. Pontianak: Fakultas Ilmu Sosial dan Ilmu Politik. Universitas Tanjungpura Pontianak Publik A, Jurnal S1 Ilmu Administrasi Negara Volume 4 Nomor 4 Edisi 1.

Aprilia, Saraswati, 2018, Analisis Pengaruh Program Keluarga Harapan (PKH) Terhadap pengentasan kemiskinan dalam perspektif Ekonomi islam (Studi Pada Pekon Pandansurat Kecamatan Sukoharjo Kabupaten Pringsewu, Publik A, Jurnal S1 Ilmu Administrasi Negara Volume 3 Nomor 2 Edisi 1.

Astutik, Windi, 2018, Pengaruh Suku Bunga Dan Nilai Tukar Terhadap Harga Saham Syariah Dengan Inflasi Sebagai Variabel Moderating (Saham Yang Terdaftar Di Jakarta Islamic Index Periode Tahun 2012 - 2016), Jurnal Jurusan Ekonomi Syariah Fakultas Ekonomi dan Bisnis Islam Institut Agama Islam Negeri Tulungagung.

Bobonis, G. \& Finan, F. 2005. Endogenous social interaction effects in school participation in rural Mexico. Mimeo, University of California at Berkeley.

BPS Tanjungbalai. Jumlah Penduduk Miskin. (On-Line) tersedia di http://www.bps.go.id (diakses, April 2019)

Indrayani, Firma Kusuma, 2014, Efektivitas Program Keluarga Harapan di Desa Sugihwaras Kecamatan Saradan Kabupaten MadiunJurnal Publika, Vol. 2 No. 3.

Juliandi, A., Irfan, I., \& Manurung, S. (2015). Metode Penelitian Bisnis : Konsep \& Aplikasi. Medan: UMSU Press.

Kartiawati, 2017, Analisis Efektivitas Program Keluarga Harapan (PKH) Dalam Pengentasan Kemiskinan Ditinjau Dari Perspektif Ekonomi Islam (Studi pada peserta PKH Kampung Bonglai Kec. Banjit Kab. Way Kanan), UIN Sunan Intan Lampung.

Kementrian Sosial, Undang-undang No. 24 tahun 2004

Kementrian Sosial, 2015, Buku Saku Pendamping dan Operator PKH

Kementrian Sosial, 2019 Pedoman Pelaksanaan Program Keluarga Harapan

Kementrian Sosial, UUD 1945 Pasal 34 ayat 1 serta Pasal 34 ayat 2 menjelaskan tentang jaminan sosial kepada masyarakat dan pasal 34 ayat 3

Kementrian Sosial,Undang-Undang nomor 23 Tahun 2002 tentang Perlindungan Anak pada pasal 1 ayat 14

Keputusan Menteri Sosial No.10/HUK/2007,

Kholif, Khodiziah Isnaini, dkk. 2014. Implementasi Program Keluarga Harapan (PKH) dalam Menanggulangi Kemiskinan di Kecamatan DawarBlandong Kabupaten Mojokerto, Univesitas Brawijaya, Jurnal Administrasi Publik Vol 2, No 4.

Komite Penanggulangan Kemiskinan Republik Indonesia Tahun 2002, Buku Putih Penanggulangan kemiskinan di indonesia

Nasution, M. I., Fahmi, M., Jufrizen, J., Muslih, M., \& Prayogi, M. A. (2020). The Quality of Small and Medium Enterprises Performance Using the Structural Equation Model-Part 
Least Square (SEM-PLS). Journal of Physics: Conference Series, 1477(2020), 1-7. https://doi.org/10.1088/1742-6596/1477/5/052052

Prawirosentono \& Suryadi 1999. Kebijakan Kinerja Karyawan. Yogyakarta: BPFE.

Sadewo, FX Sri, dkk, 2007, Buku-Masalah-Masalah Kemiskinan di SurabayaEdisi Revisi, Unesa University Press Surabaya.

Schultz, D.\& Schultz, E. S. 2010. Psychology and work today (10 edition). New York: Pearson. Sedarmayanti, 2007, Manajemen Sumber Daya Manusia, Reformasi Birokrasi, dan Manajemen Pegawai Negeri Sipil, Bandung, Refika Aditama.

Sekretariat Wakil Presiden Republik Indosia Tentang Tim Nasional Percepatan Penanggulangan Kemiskinan (2012), Perbaikan dan Perluasan Program Keluarga Harapan (PKH), Jakarta.

Sugiyono, 2016, Metode Penelitian Bisnis, cetakan ke delapan belas, Penerbir Alfabeta Bandung.

Suradi dan B Mujiyadi, 2018, Kinerja Pendamping Sosial Pada Program Penanganan Kemiskinan Dan Kelompok Rentan di Kota TarakanSosio Konsepsia Vol. 7, No. 03.

Tim Koordinasi Teknis PKH Tanjungbalai Tahun 2018, Laporan Pelaksanaan Program Keluarga Harapan (PKH) Kota Tanjungbalai Tahun 2017

TPP2K (2013), Program Keluarga Harapan (PKH): Program Bantuan Dana Tunai Bersyarat di Indonesia, Research Brief No. 42.

Utari, 2018, Kinerja Pelaksana Program Keluarga Harapan Kecamatan Di Kecamatan Ujungberung Kota Bandung Dari Tahun 2014-2016Volume 21, No. 1. 